\title{
14 RESEARCH ABOUT MOTHER'S PERCEPTION AND BEHAVIOUR ABOUT ACCIDENTS WITH CHILDREN IN
} BRAZIL

doi:10.1136/injuryprev-2012-040590w.14

A Francoia, F Aquino. CRIANAA SEGURA Safe Kids Brazil, São Paulo, Brazil

Background In 2010, Safe Kids had developed a qualitative study that showed the evident lack of knowledge among mothers related to the high incidence of accidents. In 2011, it was decided to develop a quantitative study about the same issue.

Objectives Continue the study through a quantitative survey, generate contents for disclosure and knowledge about the cause and obtain more material to help Safe Kids Brazil to guide its strategies. Methods Ipsos, a French global survey company, carried out the survey related to mother's perception and behaviour about accidents with children. 500 mothers of children under 15 years old were interviewed. They belonged to social classes A, B, C and D, were between 25 and 45-years-old and lived in five cities around the country. The research was carried out door-to-door in March 2011.

Results 52 per cent of mothers believed that their children were more exposed to risks outside their home. However, burns and falls (common accidents in the house) represented the most present risks in the minds of mothers. The most avoided accident was burning and 72 per cent of mothers have done something to prevent. The least avoided was related to children inside vehicles, only 13 per cent said to prevent it. Fall was experienced by most of 
the children of the mothers, 31 per cent. 40 per cent of mothers carry their children in cars and only 32 per cent have car seats. 